\title{
Treatment Options for Vestibular Migraine
}

\author{
Steffen Naegel, ${ }^{1}$ Manjit Matharu² and Mark Obermann ${ }^{1,3}$
}

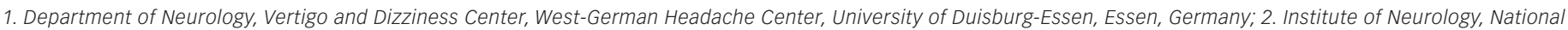
Hospital for Neurology and Neurosurgery, University College London Hospitals, London, UK; 3. Center for Neurology, Asklepios Hospitals Schildautal, Seesen, Germany

\begin{abstract}
Although vestibular migraine is a common cause of vertigo, affecting approximately $1 \%$ of the Western world's population, it remains widely under-recognized and is under-diagnosed. Diagnostic criteria for vestibular migraine were recently published in collaboration with the International Headache Society and the Bárány-Society. Trials investigating the treatment of vestibular migraine are sparse but some are now underway. This review focuses on the treatments options available for vestibular migraine, based on the existing evidence base where available. Regarding acute treatments, there are two randomized controlled trials that provide evidence for the use of triptans (zolmitriptan and rizatriptan) for the management of vestibular migraine attacks. For prophylactic treatment, the evidence base is largely non-existent, since the only multicenter randomized placebo-controlled trial testing metoprolol versus placebo is still underway. Consequently, the treatment recommendations for the prophylactic treatment of vestibular migraine are mainly based on expert opinion and the treatments guidelines for migraine with and without aura.
\end{abstract}

\section{Keywords}

Vestibular migraine, migraine with aura, vertigo, dizziness, migraine.

Disclosure: Steffen Naegel has recieved support from Allergan. Mark Obermann has received scientific support and/or honoraria from Biogen Idec, Novartis, Sanofi-Aventis, Genzyme, Pfizer, Teva and Heel. He received research grants from Allergan, Electrocore, Heel and the German Ministry for Education and Research (BMBF). Manjit Matharu serves on the advisory board for Allergan, Medtronic and St Jude Medical, and has received payment for the development of educational presentations from Allergan, Merck Sharpe and Dohme Ltd, Johnson and Johnson, and Medtronic. Steffen Naegel, Manjit Matharu, Mark Obermann: article drafting, key concepts, revision and final approval of the manuscript. No funding was received in the publication of this article.

Open Access: This article is published under the Creative Commons Attribution Noncommercial License, which permits any noncommercial use, distribution, adaptation, and reproduction provided the original author(s) and source are given appropriate credit.

Received: October 26, 2015 Accepted: February 8, 2016 Citation: US Neurology, 2016;12(1):39-42

Correspondence: Steffen Naegel, Deptartment of Neurology, University of Duisburg-Essen, Hufelandstr. 55, 45147 Essen; E: steffen.naegel@uk-essen.de

Population based studies show that primary headaches, such as migraine, are very common disorders. ${ }^{1}$ Similar accounts to vertigo and dizziness, which are are also symptoms frequently complained of. ${ }^{2}$ A significant proportion of patients report suffering these symptoms (headache, dizziness and/or vertigo) simultaneously and independently of each other. This especially accounts for migraine since up to $50 \%$ of these patients report that dizziness or vertigo accompanies their headaches at least once in a while. ${ }^{3,4}$ After a first attempt to introduce the term "vestibular migraine" (VM) was made in $1999^{5}$ the International Headache Society (IHS) and the Bárány-Society (International Society for Neuro-Otology) just recently published a consensus paper with diagnostic criteria for VM. ${ }^{6,7}$ These criteria were adopted as appendix criteria in the beta version of the third International Classification of Headache Disorders (ICHD-3 beta) to support systematic research on the pathophysiology and treatment of VM. ${ }^{8}$ In the clinical setting, these new criteria may serve to aid practitioners in the assessment of patients with VM. While vertigo specialists generally accept the existence of this entity, between headache specialists the discussion is much more controversial. Some people favour this entity, others doubt the existence of the disorder. There is an ongoing debate whether the condition is a unique entity or it simply represents a subtype of common migraine, which also includes vestibular symptoms given that migraines often occurs with predominance of other accompanying symptoms such as excessive vomiting or phonophobia. In contrast there is wide agreement that the pathophysiology of the disorder/symptom complex remains uncertain. ${ }^{9}$

Recent studies report that approximately two-thirds of patients experiencing vertigo or dizziness seek medical care because of their symptoms, but VM was diagnosed in only $20 \%$ of all patients. ${ }^{10}$ Interestingly, in routine clinical practice, clinicians reach multiple different interpretations of the symptom complex of headache and vertigo, and these interpretations are often speciality dependent. Neurologists were reported to diagnose VM in $82 \%$ of patients with this constellation, while only $64.5 \%$ of Ear, Nose, and Throat physicians made this diagnosis. ${ }^{10}$

Specific trials particularly addressing the treatment of VM are rare and most treatment guidelines are extrapolated from clinical trials on migraine with and without aura. This review summarizes the available data regarding specific treatment of VM. 


\section{Table 1: Attack Therapy-Treatment Options and Evidence}

\begin{tabular}{lll} 
Drug & Dose & Study \\
Zolmitriptan & $2.5 \mathrm{mg}$ & Randomized controlled trial \\
\hline Rizatriptan & $10 \mathrm{mg}$ & Randomized controlled trial, motion sickness \\
\hline
\end{tabular}

\section{Table 2: Prophylactic Drug-Treatment Options and Evidence}

\begin{tabular}{|c|c|c|c|}
\hline Class & Drug & $\begin{array}{l}\text { Dosage } \\
\text { (oral) }\end{array}$ & Study-type \\
\hline \multirow[t]{5}{*}{ Beta-blockers } & Metoprolol & 150 mg & Retrospective cohort analysis ${ }^{30}$ \\
\hline & & $100-200$ mg & Retrospective cohort analysis 32 \\
\hline & Propranolol & $160 \mathrm{mg}$ & Retrospective cohort analysis ${ }^{30}$ \\
\hline & & $40-160 \mathrm{mg}$ & Retrospective cohort analysis ${ }^{31,32}$ \\
\hline & & $40-160 \mathrm{mg}$ & $\begin{array}{l}\text { Prospective, open-label, } \\
\text { randomized, controlled trial }{ }^{41}\end{array}$ \\
\hline \multirow{6}{*}{$\begin{array}{l}\text { Anti-epileptic } \\
\text { agents }\end{array}$} & Valproic Acid & $600 \mathrm{mg}$ & Retrospective cohort analysis ${ }^{30}$ \\
\hline & & $600 \mathrm{mg}$ & $\begin{array}{l}\text { Cohort study, vestibulo-ocluar- } \\
\text { reflex }{ }^{33}\end{array}$ \\
\hline & Topiramate & $50 \mathrm{mg}$ & Retrospective cohort analysis ${ }^{30}$ \\
\hline & & 50-100 mg & Open-label, chart review ${ }^{43}$ \\
\hline & Lamotrigine & $75 \mathrm{mg}$ & Retrospective cohort analysis ${ }^{30}$ \\
\hline & & $100 \mathrm{mg}$ & Retrospective, open-label ${ }^{34}$ \\
\hline \multirow[t]{4}{*}{ Antidepressants } & Amitriptyline & $100 \mathrm{mg}$ & Retrospective cohort analysis ${ }^{30}$ \\
\hline & & $10 \mathrm{mg}$ & Retrospective cohort analysis ${ }^{32}$ \\
\hline & Nortriptyline & $25-75 \mathrm{mg}$ & Open-label, chart review ${ }^{43}$ \\
\hline & Venlafaxine & 37.5-150 mg & $\begin{array}{l}\text { Prospective, open-label, } \\
\text { randomized, controlled tria| }{ }^{41}\end{array}$ \\
\hline \multirow{4}{*}{$\begin{array}{l}\text { Calcium channel } \\
\text { blockers }\end{array}$} & Flunarizine & $5 \mathrm{mg}$ & Retrospective cohort analysis ${ }^{30}$ \\
\hline & & 5-10 mg & Retrospective, open-label ${ }^{32}$ \\
\hline & & $5-10 \mathrm{mg}$ & Open-label, post-marketing 38,39 \\
\hline & Cinnarizine & $\begin{array}{l}37.5-75 \mathrm{mg} \\
\text { oral }\end{array}$ & Retrospective, open-label ${ }^{36}$ \\
\hline \multirow[t]{4}{*}{ Others } & Magnesium & $400 \mathrm{mg}$ & Retrospective cohort analysis ${ }^{30}$ \\
\hline & Butterbur & $50 \mathrm{mg}$ & Retrospective cohort analysis ${ }^{30}$ \\
\hline & Extract & & \\
\hline & Clonazepam & 0,25-1 mg & Retrospective cohort analysis ${ }^{32}$ \\
\hline
\end{tabular}

\section{Methods}

A Medline search with the search term "vestibular migraine" was performed in August 2015. The search returned 152 publications of which three were clinical trials. The term "vestibular AND migraine" resulted in 483 Medline hits of which 21 were clinical trials and 125 were marked review articles. Twenty-three publications were related to the specific treatment of VM.

Due to the recent development of the consensus diagnostic criteria, the interpretation of this available data in the literature is difficult. It should be borne in mind that the patients enrolled in some of the studies would not fulfil the new diagnostic criteria for VM. Furthermore, some studies used a different terminology all together. The most common diagnoses used for the combination of migraine and vestibular symptoms were migrainous vertigo, vertiginous migraine, benign paroxysmal vertigo (of childhood), migraine-associated balance disturbance, and migraine-associated vertigo, besides VM. ${ }^{5}$

\section{Vestibular Migraine}

In the above mentioned diagnostic criteria, VM is defined as episodes of vestibular symptoms of moderate or severe intensity lasting between 5 minutes and 72 hours, of which at least 50\% are associated with migrainous headache, photophobia, phonophobia and/or visual aura in subject with a current or past history of migraine without aura or migraine with aura (MWA).

Approximately $30 \%$ of all VM attacks are not accompanied by headache. ${ }^{11-13}$ In regard to the duration of attacks some studies partly contradict the diagnostic criteria, which may vary from a few seconds (10\% of patients) to some minutes (30\%), some hours (30\%) and even up to a few days (30\%)., $, 11,12,14$ Only $10-30 \%$ of patients report vestibular symptoms with a duration between 5 and 60 minutes. ${ }^{5,13}$ In regard to the characteristics of the vertigo, a population-based survey found spontaneous rotatory vertigo (67\%) to be the most frequent vestibular symptom followed by positional vertigo (24\%). ${ }^{15}$ The vertigo itself may well change character within the attack, for example, an initial spontaneous rotatory vertigo can turn into a positional one or an illusion-of-movement type vertigo. ${ }^{16,17}$ Patients further describe an increased sensitivity to motion, especially in regard to headmovements and fast-moving visual objects. ${ }^{18,19}$ During and even after an attack, gaze-induced nystagmus, saccadic pursuit (most often vertically), central positional nystagmus and slight horizontal or vertical spontaneous nystagmus may be observed. ${ }^{5}$

Population-based studies conducted in Germany estimated the lifetime prevalence of migraine and vertigo as high as $7-16 \% .2,20$ The lifetime prevalence of VM was estimated as $1 \%$ and the one-year prevalence as $0.9 \% .{ }^{15} \mathrm{~A}$ North American survey described the presence of dizziness or vertigo at nearly $50 \%$ of patients with migraine during a severe migraine attack. ${ }^{21}$ VM may occur in any period of life, although temporal delay to the first onset of migraine is frequent and leads to an emphasis in later periods of life. 5,11,13,22 As in typical migraine, women are affected more frequently than men and familial clustering has been described. 5,12,13,22,23 VM was previously thought to be a subtype of MwA, but this association is controversial as some studies found a connection between MwA and VM, while others described patients with migraine without aura to have vestibular symptoms at least as often as MwA patients. ${ }^{5,12-14,24-26}$ It appears that in postmenopausal women the typical migraine headaches may be replaced by isolated episodes of vertigo and/or dizziness. ${ }^{27}$

From a clinical point of view, the clear cut differentiation from migraine with brainstem aura (previously called basilar-type migraine) is of significant importance since triptans are contraindicated in this condition. Less than $10 \%$ of patients with VM simultaneously meet the diagnostic criteria for basilar-type migraine. ${ }^{12,13}$ Diagnostic criteria for migraine with brainstem aura require at least two brainstem aura symptoms including dysarthria, vertigo, tinnitus, hypacusis, diplopia, ataxia or decreased level of consciousness, which are accompanied or followed by a typical migraine headache. ${ }^{8}$

\section{Medical Therapy}

Acute Treatment

There are only two randomized controlled clinical trials on the specific treatment of vestibular symptoms in migraineurs using triptans (see Table 1). ${ }^{28,29}$ One study investigated the efficacy of rizatriptan regarding 
the vertigo symptoms only in measuring the motion sickness following a complex vestibular stimulus (off-vertical axis rotation). The study recruited 25 migraine patients (23 females, $31.0 \pm 7.8$ years) with or without migraine-related dizziness. Fifteen subjects experienced vestibular-induced motion sickness after pre-treatment with placebo and thirteen of those had decreased motion sickness when pre-treated with rizatriptan $(p<0.02)$. This positive effect has to be put into perspective since it was not seen after exposure to a more intense provocative stimulation. With regard to mechanism of action, the authors suggested that rizatriptan, a serotonin-agonist, may influence the serotonergic vestibular-autonomic projections. ${ }^{29}$ Another study suggested a benefit from zolmitriptan $5 \mathrm{mg}$ in "migrainous vertigo". The explanatory power of this study is limited, however, since only ten patients were recruited and only 17 attacks were analyzed. The response to zolmitriptan was 38\% (3 of 8 episodes), whereas in the placebo group a positive effect was observed in only $22 \%$ ( 2 of 9 episodes). ${ }^{28}$

\section{Prophylactic Treatment}

Regarding prophylactic treatment of VM, no data from double-blind, placebocontrolled trials are published thus far (see Table 2). Most therapeutic recommendations for VM are currently based on the guidelines for migraine with and without aura. This seems a reasonable approach since a large retrospective cohort evaluation of 100 patients (21-72 years) analyzing standard prophylactic migraine treatment in VM patients reported a positive outcome..$^{30}$ The patients on prophylactic treatment showed a decrease in duration, intensity, and frequency of vertigo as well as its associated features $(p<0.01)$. The most frequently used drug-class in this observational study were beta-blockers taken by 49 patients (69\% on metoprolol, median dose $150 \mathrm{mg}$; 31\% on propranolol, median dose $160 \mathrm{mg}$ ). Second most frequent drug-class were anticonvulsants such as sodium-valproate (median dose $600 \mathrm{mg}$ ) and topiramate (median dose $50 \mathrm{mg}$ ) each with 6 patients, and lamotrigine (3 patients, median dose $75 \mathrm{mg}$ ). Other drugs were butterbur (4 patients, median dose $50 \mathrm{mg}$ ), amitriptyline (2 patients; 75/100 mg); flunarizine (1 patient: $5 \mathrm{mg}$ ), magnesium (3 patients; median dose $400 \mathrm{mg}$ ). A second retrospective study investigating prophylactic treatment also indicated a positive effect in patients with VM. ${ }^{31}$ This study also reported a correlation between the improvement of vestibular symptoms and the improvement of headache.

In a third retrospective study 33 patients with migraine and recurrent vertiginous attacks were evaluated. ${ }^{32}$ In the analysis of vertigo frequency, complete resolution was reported in $58 \%$ of the patients (19/33). A reduction of more than $50 \%$ was seen in nearly $25 \%(8 / 33)$, and only $18 \%$ of the patients reported a reduction of less than $50 \%$ or no response $(5+1 / 33)$. In another small study specifically investigating the effect of sodium valproate on the vestibulo-ocular reflex, sodium valproate affected neither vestibulo-ocular responses nor vestibular complaints but was effective in reducing migraine attacks in 8 of the 12 patients..$^{33}$

A retrospective, open-label study investigated the efficacy of lamotrigine in 19 patients (13 women). Monthly vertigo-attack frequency was reduced from 18.1 to 5.4 and headache frequency from 8.7 to 4.4 , which was not statistically significant. It appears that lamotrigine is more effective for vestibular symptoms than for headaches. ${ }^{34}$ This is especially interesting since it was previously shown that lamotrigine is more effective for aura than for migraine headache. ${ }^{35}$
Calcium-channel-blockers appear to be a reasonable treatment choice in VM since they are frequently used in migraine as well as vertigo. In a retrospective, single-center, open-label, study cinnarizine was tested regarding its effects on VM and migraine associated with vertigo. ${ }^{36}$ The study included 24 patients (23 female) with VM and 16 (12 female) suffering from basilar-type migraine. Significant reduction was seen in mean vertigo frequency as well as in mean headache frequency, duration and intensity $(p<0.001)$.

For the calcium channel antagonist, flunarizine there is one randomized controlled trial evaluating the efficacy of flunarizine $10 \mathrm{mg}$ in 48 "migrainous vertigo" patients in comparison to standard care with regular vestibular exercises and symptomatic use betahistine $16 \mathrm{mg}$, three times a day (TDS) for 2 days and paracetamol $1 \mathrm{~g}$ as needed (PRN). ${ }^{37}$ Flunarizine led to reduction of vertigo frequency $(p=0.010)$ and severity $(p=0.046)$. In contrast, the headaches (severity and frequency) were not significantly reduced.

In two large open-label post-marketing studies, flunarizine was reported to be effective for migraine (compared to propranolol) and vertigo (compared with betahistine). ${ }^{38,39}$ The results from these big cohorts cannot be directly related to the response to VM, since both studies evaluated the two symptoms independantly of each other. A fourth analysis of this agent evaluated the efficacy of flunarizine and propranolol in VM and found both drugs to be comparably effective. While $68 \%$ of the patients responded to flunarizine $(p<0.001)$ improvement of symptoms was seen in $73 \%$ of the patients on propranolol $(p<0.001) .{ }^{40}$

A recent prospective, randomized, controlled active comparator study investigated the effectiveness of venlafaxine and propranolol for the prophylaxis of VM in 64 patients. ${ }^{41}$ Endpoints were the "Dizziness Handicap Inventory", the "Vertigo Severity Score" and the number of vertiginous attacks. At 4 months all endpoints showed significant improvement and treatment effects were similar in both groups ( $p>0.05$ ). Additionally, "Beck Depression Inventory"-testing was performed which only improved in the venlafaxine arm of the study.

Even for drugs not specially tested in migraine with or without aura or those previously shown to be ineffective in these conditions, positive data exist regarding treatment of VM; these drugs include benzodiazepines, pizotifen, dothiepin, selective serotonin reuptake inhibitors (SSRI), and acetazolamide. ${ }^{32}$ However, data are insufficient to derive therapeutic recommendation for any one of those medications. Furthermore, these studies were performed prior to the current definition of VM and inconstant criteria were used across studies. Hopefully this ambiguity will no longer feature in future studies and the recent consensus diagnostic criteria are likely to lead to more comparable and higher quality studies.

\section{Non-medical Treatment Options}

An Australian study investigated the effect of a structured nine-week vestibular rehabilitation exercise programme as add-on to medication or as stand-alone treatment. ${ }^{42}$ Thirty-six patients with daily vestibular symptoms (VM 20, vestibular impairment 16) attended five therapy appointments during a six-month period. Although starting from a different level of impairment, both groups benefited comparably from this intervention. The effect was not found to differ between different medication regimes, which led the authors to conclude that the 
rehabilitation therapy may be effective in VM regardless of the medical prophylactic therapy used.

There is only very limited data on the effect of behavioural therapies and modification on VM. One study investigated the cessation of caffeine in 34 patients. ${ }^{43}$ Approximately $14 \%$ of patients reported an improvement of their symptoms. To put this into perspective, topiramate reduced symptoms in $25 \%$ and nortriptyline in nearly $50 \%$ of patients.

\section{Treatment Recommendations and Conclusions}

Due to the lack of high quality trials in this condition the treatment recommendations for VM are currently similar to those for migraine with or without aura. Some of the following treatment recommendations are based on the authors' experience.

The available literature suggests zolmitriptan ( $5 \mathrm{mg}$ ) as first choice acute therapy for VM. Rizatriptan may also be used and it is likely that the other triptans are just as effective. Patients with nausea and/or vomiting may benefit more from non-oral applications (i.e., nasal spray, or subcutaneous injections). If triptans are not suitable, symptomatic therapy with nonsteroidal anti-inflammatory drugs, acetylsalicylic acid, metoclopramide or dimenhydrinate may be another option, especially since the latter three are available in intravenous formulations (acetylsalicylic acid $1000 \mathrm{mg}$, metoclopramide $10 \mathrm{mg}$ or dimenhydrinate $62.5 \mathrm{mg}$ ). Triptans should not be used in patients fulfilling criteria for VM and migraine with brainstem aura.
Data regarding prophylactic medications for VM are not sufficiently robust to deviate from the guidelines for treatment of migraine with or without aura. The agents that can be considered include beta-blockers (propranolol 80-240 mg, metoprolol 50-200 mg, bisoprolol 5-10 mg), calcium channel blockers (flunarizine 5-10 mg) and anticonvulsants (topiramate 50-100 mg, sodium-valproate 1000-1500 mg). In patients suffering chronic migraine with vestibular symptoms ( 15 headache days per month, of which at least 8 are migrainous, lasting for longer than 3 months) consider topiramate or at least two courses of onabotulinumtoxin type $\mathrm{A}$ injections, ${ }^{44}$ albeit that no data exist for the treatment of VM specifically. If depression is comorbid with VM, amitriptyline may be a reasonable choice. Patients with predominant vertigo or dizziness with typical aura duration and those who simultaneously fulfil criteria for brainstem aura might be successfully treated with lamotrigine (25-100 mg) ${ }^{34}$

Hitherto, controlled data for the treatment of VM are sparse; while some data from small randomized controlled trials exist for the attack treatment, no data from high quality trials exist for the prophylactic regimes. Retrospective analyses and open label studies suggest, that the established treatments for migraine with and without aura may be effective in VM as well. However, there remains an uncertainty whether one of those treatment options is superior to others and whether more specific treatment options exist. An ongoing multicenter randomized placebo-controlled trial (metoprolol 95 mg vs. placebo) called PROVEMIGtrial is currently underway.
1. Rasmussen BK, Jensen R, Schroll M, Olesen J, Epidemiology of headache in a general population-a prevalence study, $J$ Clin headache in a general population-c

2. Neuhauser HK, von Brevern M, Radtke A, et al,. Epidemiology of vestibular vertigo: a neurotologic survey of the general population, Neurology, 2005;65(6):898-904.

3. Vukovic V, Plavec D, Galinovic I, Lovrencic-Huzjan A, et al., Prevalence of vertigo, dizziness, and migrainous vertigo in patients with migraine, Headache, 2007:47(10):1427-35.

4. Cha YH, Lee H, Santell LS, Baloh RW. Association of benign recurrent vertigo and migraine in 208 patients, Cephalalgia, 2009:29(5):550-5.

5. Dieterich $\mathrm{M}, \mathrm{Brandt} \mathrm{T}$, Episodic vertigo related to migraine $(90$ cases): vestibular migraine?, J Neurol, 1999;246(10):883-92.

6. Lempert T, Olesen J, Furman J, et al., [Vestibular migraine: diagnostic criteria: consensus document of the Barany Society and the International Headache Society], Nervenarzt 2013;84(4):511-6

7. Lempert T, Olesen J, Furman J, et al., Vestibular migraine: diagnostic criteria, J Vestib Res, 2012;22(4):167-72.

8. Headache Classification Subcommittee of The International Headache Society. The International Classification of Headache Disorders 3rd edition (beta version), Cephalalgia, 2013;33(9):629-808.

9. Stolte B, Holle D, Naegel S, Vestibular migraine, Cephalalgia ، 2015;35(3):262-70

10. Millen SJ, Schnurr CM, Schnurr BB, Vestibular migraine: perspectives of otology versus neurology, Otol Neurotol, 2011;32(2):330-7.

11. Cutrer FM, Baloh RW, Migraine-associated dizziness, Headache, 1992;32(6):300-4.

12. Johnson GD, Medical management of migraine-related dizziness and vertigo, Laryngoscope, 1998;108(1 Pt 2):1-28.

13. Neuhauser $\mathrm{H}$, Leopold $\mathrm{M}$, von Brevern $\mathrm{M}$, et al., The interrelations of migraine, vertigo, and migrainous vertigo, Neurology 2001:56(4):436-41.

14. Kayan A, Hood JD, Neuro-otological manifestations of migraine, Brain, 1984;107 ( Pt 4):1123-42.

15. Neuhauser HK, Radtke A, von Brevern M, et al., Migrainous vertigo: prevalence and impact on quality of life, Neurology, 2006;67(6):1028-33.
16. Slater R, Benign recurrent vertigo, J Neurol Neurosurg Psychiatry, 1979:42(4):363-7.

17. Moretti G, Manzoni GC, Caffarra P, Parma M, "Benign recurrent vertigo" and its connection with migraine, Headache, 1980;20(6):344-6

18. Waterston J, Chronic migrainous vertigo, J Clin Neurosc 2004;11(4):384-8

19. Drummond PD. Triggers of motion sickness in migraine sufferers, Headache, 2005:45(6):653-6.

20. Yoon MS, Katsarava Z, Obermann M, et al., Prevalence of primary headaches in Germany: results of the German Headache Consortium Study I Headache Pain, 2012:13(3):215-23.

21. Calhoun AH, Ford S, Pruitt AP, Fisher KG. The point prevalence of dizziness or vertigo in migraine-and factors that influence presentation, Headache, 2011;51(9):1388-92.

22. Cass SP, Furman JM, Ankerstjerne K, Migraine-related vestibulopathy, Ann Otol Rhinol Laryngol, 1997;106(3):182-9.

23. Oh $A K$, Lee $H$, Jen JC, Familial benign recurrent vertigo. Am 」 Med Genet, 2001:100(4):287-91.

24. Kuritzky A, Toglia UJ, Thomas $D$, Vestibular function in migraine, Headache, 1981;21(3):110-2.

25. Cha YH, Baloh RW, Migraine associated vertigo, I Clin Neurol, 2007:3(3):121-6.

26. Akdal G, Ozge A, Ergor G, The prevalence of vestibular symptoms in migraine or tension-type headache, J Vestib Res, 2013;23(2):101-6

27. Lempert T, Neuhauser H, Daroff RB, Vertigo as a symptom of migraine, Ann N Y Acad Sci, 2009:1164:242-51.

28. Neuhauser $\mathrm{H}$, Radtke $\mathrm{A}$, von Brevern $\mathrm{M}$, Lempert $\mathrm{T}$, Zolmitriptan for treatment of migrainous vertigo: a pilot randomized placebo-controlled trial, Neurology, 2003;60(5):882-3.

29. Furman JM, Marcus DA, Balaban CD, Rizatriptan reduces vestibular-induced motion sickness in migraineurs, $J$ Headache Pain, 2011:12(1):81-8.

30. Baier B, Winkenwerder E, Dieterich M, "Vestibular migraine": effects of prophylactic therapy with various drugs. A retrospective study, I Neurol, 2009;256(3):436-42.

31. Bikhazi P, Jackson C, Ruckenstein MJ, Efficacy of antimigrainous therapy in the treatment of migraine-associated dizziness, Am Otol, 1997;18(3):350-4

32. Maione A, Migraine-related vertigo: diagnostic criteria and prophylactic treatment, Laryngoscope, 2006;116(10):1782-6.

33. Gordon CR, Kuritzky A, Doweck I, Vestibulo-ocular reflex in migraine patients: the effect of sodium valproate, Headache, 1993:33(3):129-32.

34. Bisdorff AR, Treatment of migraine related vertigo with lamotrigine an observational study, Bull Soc Sci Med Grand Duche Luxemb, 2004(2):103-8.

35. Lampl C, Katsarava Z, Diener HC, Limmroth V, Lamotrigine reduces migraine aura and migraine attacks in patients with migraine with aura, J Neurol Neurosurg Psychiatry, with migraine with

36. Taghdiri F, Togha M, Razeghi Jahromi S, Refaeian F, Cinnarizine for the prophylaxis of migraine associated vertigo: a retrospective study, SpringerPlus, 2014;3:231

37. Lepcha A, Amalanathan S, Augustine AM, et al., Flunarizine in the prophylaxis of migrainous vertigo: a randomized controlled trial, Eur Arch Otorhinolaryngol, 2014:271(11):2931-6.

38. de Bock GH, Eelhart J, van Marwijk HW, et al., A postmarketing study of flunarizine in migraine and vertigo, Pharm World Sci. 1997;19(6):269-74

39. Verspeelt J, De Locht P, Amery WK. Postmarketing study of the use of flunarizine in vestibular vertigo and in migraine, Eur $J$ Clin Pharmacol, 1996;51(1):15-22.

40. Van Ombergen A, Van Rompaey V, Van de Heyning P, Wuyts E, Vestibular migraine in an otolaryngology clinic: prevalence, associated symptoms, and prophylactic medication effectiveness, Otol Neurotol, 2015:36(1):133-8.

41. Salviz M, Yuce T, Acar H, et al., Propranolol and venlafaxine for vestibular migraine prophylaxis: A randomized controlled trial, Laryngoscope, 2016;126(1):169-74.

42. Vitkovic J, Winoto A, Rance G, et al., Vestibular rehabilitation outcomes in patients with and without vestibular migraine I Neurol, 2013;260(12):3039-48.

43. Mikulec AA, Faraji F, Kinsella $\sqcup$, Evaluation of the efficacy of caffeine cessation, nortriptyline, and topiramate therapy in vestibular migraine and complex dizziness of unknown etiology, Am J Otolaryngol, 2012;33(1):121-7.

44. Dodick DW, Turkel CC, DeGryse RE, et al., OnabotulinumtoxinA for treatment of chronic migraine: pooled results from the double-blind, randomized, placebo-controlled phases of the PREEMPT clinical program, Headache, 2010;50(6):921-36. 